\title{
Julião Machado: arte gráfica exalando a tinta da impressão

$\mathbb{P}$

ROJETO GRÁFICO inusitado. Edição primorosa. Conteúdo surpreendente.

Essas são as impressões iniciais de uma primeira visada do livro de Letícia Pedruzzi Fonseca (2016), Julião Machado e as revistas ilustradas no Brasil 1895-1898, editado pela Blucher. Sensações que se confirmam após o atento folhear das páginas que - a exemplo da produção do biografado - conjuga imagem e texto em diálogo permanente, completando-se e enriquecendo a informação.

A proposta de projeto gráfico inovador expressa no livro não seria surpreendente vinda de uma professora e pesquisadora da área do design da Universidade Federal do Espírito Santo, que se doutorou sob orientação de Rafael Cardoso e cuja tese resultou na publicação aqui em análise. A estética da edição, que se vale das páginas criadas por Julião Machado (1863-1930) em várias de suas publicações, conduz o leitor de imediato à atmosfera de seu tempo. A ilustração, nesse caso, é utilizada como documento de um tempo específico, do fin de siècle no Rio de Janeiro, quando laivos de modernidade se impõem a serviço da jovem República, em várias dimensões. A começar pela modernidade técnica da impressão, do desenho gráfico, da introdução do art-nouveau configuradas e perceptíveis, justamente, no trabalho de Julião Machado, que além de caricaturista foi ilustrador e diretor artístico de diversos jornais, revistas e livros, assim como jornalista da imprensa escrita, autor de comédias dramáticas, e cenógrafo.

O encantamento proveniente do trato gráfico da obra se desdobra na leitura crítica de seu conteúdo, que revelou - para além do escrutínio da vasta produção do artista -, novas questões da história gráfica do país, preenchendo lacunas persistentes na historiografia da área. Com metodologia e análise técnica científicas da produção do caricaturista e ilustrador, a autora desvelou a obra daquele que sempre é apresentado como o "artista que mudou o padrão gráfico das revistas ilustradas brasileiras". Contudo, desvencilhando-se desse quase clichê, que permanentemente rotula Julião Machado, a autora ultrapassa a visão dos estudiosos tradicionais da arte gráfica no país, que lhe conferem reiteradamente apenas a inserção entre a velha e a nova geração de ilustradores gráficos - o que já seria até relevante -, para situá-lo como protagonista e agente decisivo do trato da crônica de costumes e das novas técnicas empregadas, que inovavam, agilizavam e barateavam a produção. Ou, como lembra Rafael Cardoso no prefácio da obra: “O maior mérito do livro de Letícia Pedruzzi é justamente o de reconstituir essa trajetória e restaurar Julião Machado ao seu devido lugar na história. Não mais como elo apenas, mas como protagonista de uma narrativa ainda pouco lembrada e conhecida".

Mas, vamos por partes.

Já no primeiro capítulo, a autora introduz o "Panorama da publicação 
periódica ilustrada brasileira no século XIX", no qual apresenta balanço atualizado da produção dos ilustradores dos oitocentos. Analisa a rica bibliografia recente, que evoca a era de ouro da caricatura brasileira, uma das manifestações do impresso mais prolíficas do Império, seminais na crítica de costumes e especialmente na análise política. Caricatura que fez as vezes da palavra impressa no país de baixo letramento. De Henrique Fleuiss (1824-1882), passando por Angelo Agostini (1843-1910) e chegando a Raphael Bordalo Pinheiro (1846-1905) recupera suas respectivas produções e ingressa pelos meandros técnicos que pautaram a produção dos artistas do lápis. Após essa abordagem, que se traduz em trato didático sobre os suportes e técnicas do impresso - sobretudo para o leitor leigo no assunto - emerge o primeiro diferencial: a transformação da imagem esfumaçada de seus predecessores, para aquela do traço firme e limpo de Julião Machado, delimitando cenas e personagens. A distinção de técnicas é flagrada na apreensão plástica das páginas, perceptível a olho nu, mesmo por olhares não treinados na análise de imagens. Mas aos poucos vão surgindo as novas revelações, que decodificam as técnicas subjacentes ao desenho limpo de Machado, que conjugam texto e imagem e - mais surpreendente - impressos por uma só máquina, procedimento incomum para a época.

A compreensão da bagagem do artista e as condições de sua atuação inédita são dadas no capítulo seguinte, "Julião Machado e a mudança do padrão gráfico das revistas ilustradas brasileiras". Nesse, dedica-se, inicialmente, ao trato plural de sua biografia, reveladora dos diferenciais de formação em relação aos contemporâneos. Natural de São Paulo de Luanda, capital de Angola, era filho de abastado comerciante, o que lhe propiciou estudos em Lisboa e Coimbra e o convívio com a boêmia lisboeta, do "Grupo do Leão de Ouro", que reunia nomes como Columbano, Raphael Bordalo Pinheiro, Manuel Gustavo, Antônio Ramalho, João Vaz, entre outros. Dessa convivência privilegiada nascem os convites para ingresso na imprensa local. Ciente de sua vocação artística, vai a Paris e participa do ateliê de Fernand Cormon, frequentado na década de 1880 por Toulouse-Lautrec e Van Gogh. Não por acaso, Pedruzzi trata também das eventuais convergências plásticas entre Julião Machado e Lautrec.

Aos poucos a autora reconstitui o artista revolucionário, as práticas que introduziu na impressão do periodismo da época, balizando o grande ciclo das revistas litografadas na última década do século XIX, ao inaugurar aquele do desenho zincografado nas revistas $A$ Cigarra (1895-1896) e A Bruxa (18961897), criadas pela dupla Julião Machado (1863-1930) e Olavo Bilac (18651818). Na primeira, contavam com os capitais do banqueiro Manoel Ribeiro Junior e, na segunda, com o aporte financeiro do português João de Souza Lage, futuro proprietário do jornal $O$ Paiz, do Rio de Janeiro.

A análise gráfica e a trajetória de ambas as publicações são tratadas em capítulos próprios, que também vão além dos tradicionais estudos que fartamente têm merecido as duas revistas de sucesso a seu tempo. Para isso se utiliza da efervescência recente de pesquisas sobre a imprensa periódica, que produziram novas metodologias de abordagem, sistematizaram informações e conferiram 
as potencialidades desse suporte documental. A começar pela análise estrutural dos periódicos, fornecendo os dados colhidos na pesquisa física do objeto, como formato, tipo de papel, número de páginas, periodicidade, preços, endereços, proprietários, colaboradores, gráficas, diagramação, família tipográfica utilizada, estilos de títulos e das ilustrações. Detém-se em subcapítulos que tratam especificamente da Capa, do Miolo, das Ilustrações Especiais e das Vinhetas.

Sem descuidar de seu personagem principal - que se conjuga na figura de Julião Machado, mas também nas revistas $A$ Cigarra e A Bruxa-, é analisada a participação de um jovem Bilac, então de apenas 29 anos, já afamado, mas distante da consagração posterior como poeta parnasiano e militante ligado à causa da defesa nacional e do serviço militar obrigatório. É um Bilac iniciante, que se vale da crônica sucinta para a crítica política elegante, enquanto Machado o espelha no mesmo diapasão por meio do desenho. A sátira e o humor confirmavam a ligação afinada, traduzida na palavra e no desenho das respectivas habilidades. Bilac e Machado, ao responderem respectivamente pela direção literária e artística das revistas mencionadas, acabaram por “cronicar" o Rio de Janeiro, pelo texto e pelo traço, reproduzindo as "coisas miúdas", os fatos da hora, registrados no calor dos acontecimentos.

Contudo, é a análise pormenorizada que revela a descoberta de recursos técnicos para otimização do impresso. Recursos que ressaltam não só na análise especifica de Julião Machado e suas inovações, mas ao longo dos demais capítulos, ao decodificar as revistas $A$ Cigarra, A Bruxa, e mesmo a publicação da revista $O$ Mercúrio, em que o artista teve participação no ano 1898. Em relação às duas revistas iniciais, fica comprovado que em $A$ Cigarra deu-se a experiência da transição, e em A Bruxa, o resultado dos experimentos. Já em O Mercúrio, de 1898, atesta-se a adesão das técnicas introduzidas por Machado e a emergência, a partir dessa publicação, da nova geração de caricaturistas que atuariam nos primórdios do século XX, sob inegável influência de Julião Machado: Raul (Raul Pederneiras), K. Lixto (Calixto Cordeiro) e Bambino.

O "pulo de gato" da pesquisa resulta justamente da análise laboratorial e científica da produção do artista, recurso só possível para quem domina as técnicas do impresso e dispõe de aparelhamento avançado para análises microscópicas que decodificam e desvendam a produção das "imagens híbridas", por ele inauguradas. Logo, seu trabalho introduz nova metodologia para o trato da arte gráfica e do design, trazendo à luz suas várias camadas constitutivas.

Com a preocupação da análise vertical do objeto, a autora atesta que o desenho de Machado se firma no traço a bico de pena, definido pela linha de contorno sempre impressa em preto. Nas revistas a duas cores emprega o pincel, o Ben-Day e o espargido. Com o pincel, preenchia áreas de cor chapada e traços soltos; com o Ben-Day - processo gráfico similar ao pontilhismo dos impressionistas, assim denominado em alusão ao nome de seu criador, o ilustrador e impressor norte americano Benjamin Henry Day, Jr. (1838-1916) -, preenchia e dava acabamento às ilustrações nos limites das áreas definidas, valendo-se de texturas reticuladas e de listras; com a técnica do espargido utilizava os respingos, por vezes usado como textura de fundo das 


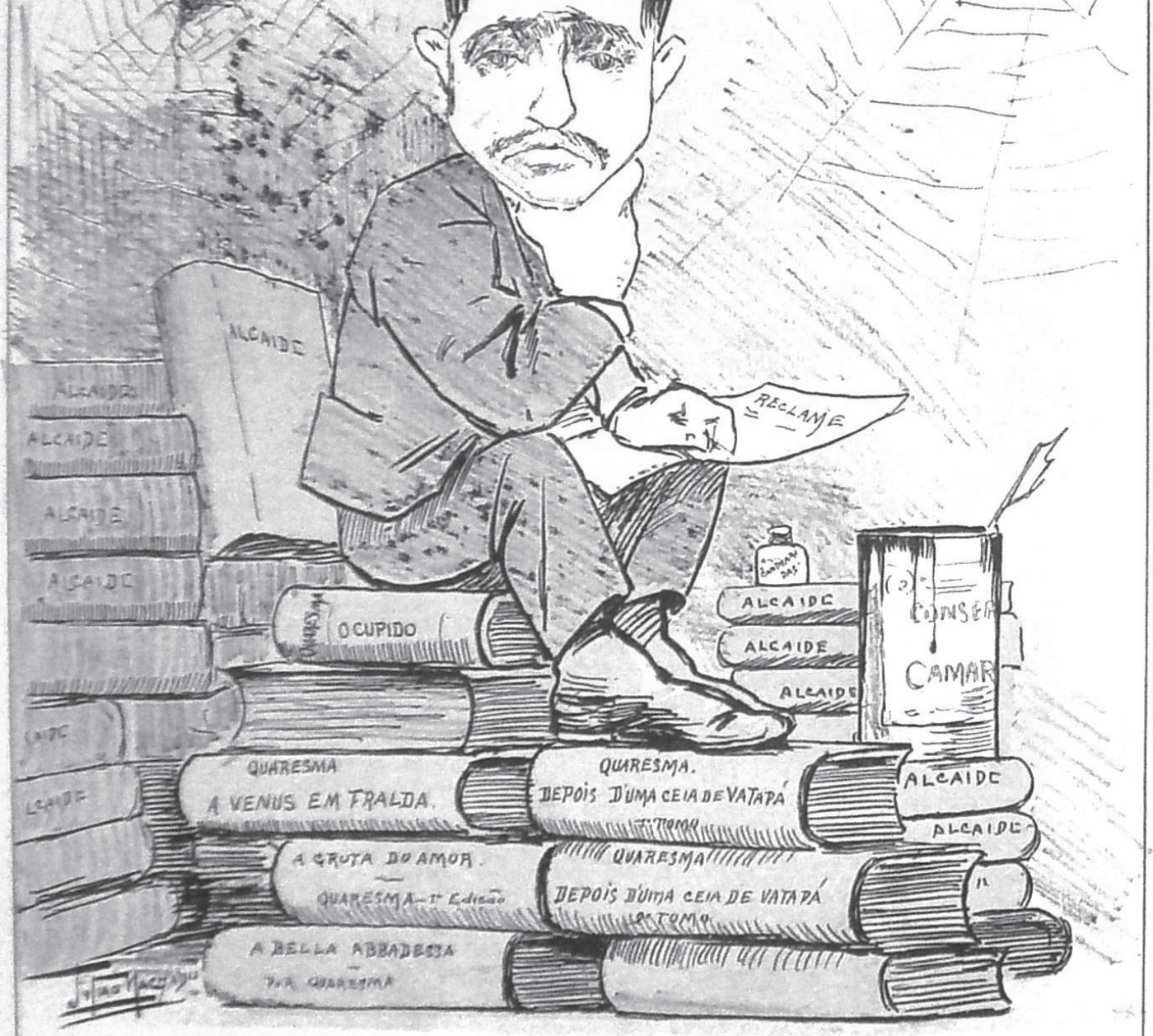

- Be a pelle de bacalhío dème para encidernaçōes - ai, que dinheirama, ai, que dinheirama!...

A Bruxa, n.12, 1896, p.8. 
imagens ou como preenchimento das figuras definidas pelo bico de pena.

E mais: foi identificada a técnica de simulação da xilogravura, procedendo à raspagem da área entintada da superfície litográfica, onde se trabalha o branco.

Todos esses procedimentos técnicos, que superavam o monocromatismo vigente, eram por vezes utilizados num só desenho, resultando seu diferencial de hibridização por sobreposição das várias técnicas, trato visual único para a época, que o singularizava entre seus pares, além de inaugurar a zincografia e a fotogravura, em experiências isoladas.

Vale ressaltar que a autora dedica vários parágrafos a analisar e demonstrar a proximidade dos resultados obtidos pelo autor em face dos propalados cartazes fin-de-siècle de Mucha (1860-1939) e Toulouse-Lautrec (1864-1901), o que comprova iconograficamente ao reproduzir, em detalhes, os desenhos desses artistas coevos. O que não seria surpreendente em artista que vivenciara in locu a produção francesa e que estava inserido na atmosfera artística renovadora de sua época, por meio da efervescente circulação transnacional de ideias e imagens do período.

Mas o que ressalta e fica patenteada de forma didática, ao longo de todo o livro, é a nova visualidade introduzida por Julião Machado, com seu método particular de construção das imagens, adotando o traço firme do desenho, os vários tipos de preenchimento e a produção geral do impresso com apenas uma tecnologia. E essa comprovação só foi possível por meio do exame microscópico de superfícies impressas, conforme utilizado por Pedruzzi.

Muito já se disse sobre as inovações de Julião Machado. Mas nessa publica- ção se vai além, pois não só desvenda as técnicas e justifica a nova visualidade gráfica por ele introduzida - proposta fundante do trabalho -, mas percorre com olhar problematizado os caminhos da história gráfica, da imprensa brasileira, da influência francesa na perspectiva da circularidade transnacional de ideias e modelos, da revolução técnica a que se assistia em âmbitos vários, da emergência da modernidade nas artes plásticas, das mediações propiciadas pela revista no universo da leitura.

Se reparo houver à edição, inevitável em trabalhos de tantos experimentos, seria ao corpo de letra das legendas e às cores utilizadas, que dificultam sua leitura, contrastando com a limpeza do texto escorreito, claro e de narrativa elucidativa. Detalhe de somenos importância em obra que guarda harmonia plástica e textual.

Por fim, cabe sublinhar que a abrangência da análise deriva, em boa parte, do uso competente da revista como fonte, metodologia que se firmou internacionalmente e que na atualidade acadêmica nacional encontra grande receptividade. Embora os propósitos de Letícia Pedruzzi fossem a obra e o lugar de Julião Machado na histórica gráfica do país, ao utilizar-se do suporte revista como documento e explorá-la em suas tantas dimensões, ultrapassou seus propósitos explícitos e iluminou generosamente etapa decisiva da história cultural do país.

\section{Referência}

FONSECA, L. P. Uma revolução gráfica: Julião Machado e as revistas ilustradas no Brasil, 1895-1898. São Paulo, Blucher, 2016. 
Ana Luiza Martins é doutora em história social pela Faculdade de Filosofia, Letras e Ciências Humanas da Universidade de São Paulo. @ - analuizac@uol.com.br / https://orcid.org/0000-0002-7100-5613.

Recebido em 16.9.2018 e aceito em 24.10.2018.

I Instituto de Estudos Brasileiros, Universidade de São Paulo, São Paulo, São Paulo, Brasil. 